Georgia State University

ScholarWorks @ Georgia State University

$10-8-2013$

\title{
The sound of social cognition: Toddlers' understanding of how sound influences others
}

Rebecca Williamson

Georgia State University, rawillia@gsu.edu

Rechele Brooks

Andrew N. Meltzoff

Follow this and additional works at: https://scholarworks.gsu.edu/psych_facpub

Part of the Cognitive Psychology Commons

\section{Recommended Citation}

Author Accepted Manuscript version of article published as: Williamson, R. A., Brooks, R., \& Meltzoff, A. N. (2013). The sound of social cognition: Toddlers' understanding of how sound influences others. Journal of Cognition and Development. Advance online publication. doi: 10.1080/15248372.2013.824884

This Article is brought to you for free and open access by the Department of Psychology at ScholarWorks @ Georgia State University. It has been accepted for inclusion in Psychology Faculty Publications by an authorized administrator of ScholarWorks @ Georgia State University. For more information, please contact scholarworks@gsu.edu. 
Author's Accepted Manuscript

To be published in:

JOURNAL OF COGNITION AND DEVELOPMENT

\title{
The Sound of Social Cognition: Toddlers' Understanding of How Sound Influences Others
}

\author{
Rebecca A. Williamson \\ Georgia State University \\ Rechele Brooks \& Andrew N. Meltzoff \\ University of Washington
}

\begin{abstract}
Understanding others' perceptions is a fundamental aspect of social cognition. Children's construal of visual perception is well investigated, but there is little work on children's understanding of others' auditory perception. The current study assesses toddlers' recognition that producing different sounds can affect others differentially - auditory perspective taking. Two- and three-year-olds were familiarized with two objects, one loud and one quiet. The adult then introduced a doll, and children were randomly assigned to one of two goals: either to wake the doll or to let her sleep. Children's object choice and the sound intensity they produced significantly varied in the predicted direction as a function of the goal task. These findings reveal young children's understanding of the effects of sound on other people's behavior and psychological states.
\end{abstract}

Successful social interaction involves understanding and taking into account other people’s perception and attention. Previous studies have primarily investigated young children's understanding of others' visual perspective. Understanding what a person is looking at helps in

We acknowledge funding from the National Science Foundation (SMA-0835854) and thank the families who participated in this study. 
decoding their emotions (e.g., Moses, Baldwin, Rosicky, \& Tidball, 2001; Repacholi, 1998), and directing their attention is integral to communication (Baldwin \& Markman, 1989; Bangerter, 2004). However, auditory information can also specify distal objects of attention - a siren promotes a discussion of fire trucks with a child, and the bang of a judge's gavel conveys a shared conventional meaning to adults. We examine toddlers' nascent understanding of the effects that their own self-produced sounds have on others.

Much is known about children's understanding of others' visual perception. Before their first birthdays infants process the "aboutness" of visual contact, taking into account the psychological connection between looking behavior and a distal target (e.g., Brooks \& Meltzoff, 2002; Flom, Lee, \& Muir, 2007; Johnson, Ok, \& Luo, 2007; Lee, Eskritt, Symons, \& Muir, 1998; Phillips, Wellman, \& Spelke, 2002; Woodward, 2003). Older children become more adept at recognizing what others can and cannot see. Two-year-olds register whether an object is visible or hidden from another person's viewpoint, (Level-1 perspective-taking, e.g., Flavell, 1992; McGuigan, 2007; Moll \& Tomasello, 2006) and 3- to 4-year-olds understand that two people can have a different visual perception of the same object (e.g., Flavell, Everett, Croft, \& Flavell, 1981; Moll \& Meltzoff, 2011; Moll, Meltzoff, Merzsch, \& Tomasello, 2013).

Relatively little is known about children's understanding of others' auditory perception. In experiments testing children's reactions to others' emotional displays, 18-month-olds witnessed an adult perform a "forbidden act," such as pressing a button that made a buzzing sound, which prompted an angry response by another adult (Repacholi \& Meltzoff, 2007; Repacholi, Meltzoff, \& Olsen, 2008). The toddlers were unlikely to imitate the sound-making act when the previously angry adult was watching them. They readily performed the noisy act, however, if the previously angry adult was not directing visual attention at the children but could hear them. Toddlers took into account the adult's visual but not auditory perception when the adult's back was turned or her eyes were closed.

Melis, Call, and Tomasello (2010) found that older children take into account whether they will be heard when performing a forbidden action. Three-year-olds chose to open a quiet door (instead of a loud one) to retrieve a prohibited toy when an adult was nearby. Moll, Carpenter, and Tomasello, (in press) also reported that 2- and 3-year-olds track what auditory experiences are familiar (i.e., recently heard) versus new to others. Additionally, 3-year-olds are reported to recognize that other people might hear a sound from a distance, such as from another room (Yaniv \& Shatz, 1988). Thus, between 18 months and 3 years children deepen their understanding about others’ auditory perceptions (a form of Level-1 perspective taking).

These previous studies have focused on the presence or absence of sound, a simple on-off factor. The current experiment examines whether children understand that the type of sound produced may also influence a social situation. We employ a novel method examining how children use sound in relation to others' waking and sleeping. This is an event that children 
encounter in their own experience and through observations of siblings and peers. We tested children during the potential transitional period between 18 months and 3 years of age.

In the current procedure, an adult demonstrates to the children that novel objects have the property of either being loud or quiet when picked up and handled. Children are then asked to wake up a doll or to let her sleep, and are presented with the objects in a paired-comparison test format. The test question is whether children change their choices and behavior as a function of the experimental condition. Children might change their object choice. Even more directly, though, they should change the sound intensity they produce when manipulating the objects depending on the goal of the scenario. If children understand that noise affects others, they should make loud noises for the waking goal and purposely make measurably quieter noises for the sleeping goal. Of theoretical interest to the ontogeny of this behavior, we also investigate whether having siblings influences children’s performance on the task.

\section{Methods}

\section{Participants}

Two age groups were tested: 2 -year-olds ( $n=24 ; M=2.2$ years, $S D=0.14$ months; 11 males) and 3-year-olds ( $n=24 ; M=3.1$ years, $S D=0.13$ months; 11 males). Children were recruited through a university’s participant list. According to parental report of racial/ethnic identity, $83 \%$ of the children were White, 15\% Black, 4\% Hispanic, and 2\% reported as more than one racial identity. Direct measures of socioeconomic status were not obtained for this sample, but past research with this pool suggests that the sample was generally middle- to uppermiddle class. Four additional children did not complete the procedure, and another two children's data were excluded due to experimenter error.

\section{Materials}

Four novel objects were constructed (22-cm long, 4-cm diameter) using plastic, clear tubes (Figure 1). Two contained multicolored feathers or glitter, which yielded a very soft sound when the tube was shaken. The other two contained bells or beads, which produced a loud sound when shaken. The tubes were sealed, and the materials could be seen through the cylinders. The tubes were paired, allowing two trials for each child: (a) bells versus feathers and (b) beads versus glitter flecks. Pilot testing suggested the two objects in each pair were equally attractive to 2- and 3-year-olds. A baby doll (24 cm x $16 \mathrm{~cm} \mathrm{x} 4 \mathrm{~cm}$ ) was also used. The doll was tucked into a bassinet with a blanket that came up to its chin. The doll's eyes were open.

\section{Procedure}

Children were tested individually in a university laboratory room, and their behavior was video recorded for subsequent analysis. Each child was randomly assigned to one of two independent groups (the wake and the don't wake group), each including a familiarization and a test phase. Which object was presented on the right was counterbalanced between children. 
Familiarization phase. In familiarization, children were introduced to the two pairs of objects and to the auditory consequences of shaking them. This period was also used to establish baseline preferences for each object and the sound intensity children typically produced.

The experimenter first introduced one of the two objects of a loud/quiet pair. She drew the child's attention to it (“Look!”), shook the object, and asked the child, “Can you hear it?” She then removed the object from the child's view and introduced the second object of the pair in the same way. Children next were presented with a paired-comparison choice of the objects. After their choice, the children were given a 10 -s period to manipulate the objects (with both objects available). Then, the experimenter introduced the second set using the same procedure.

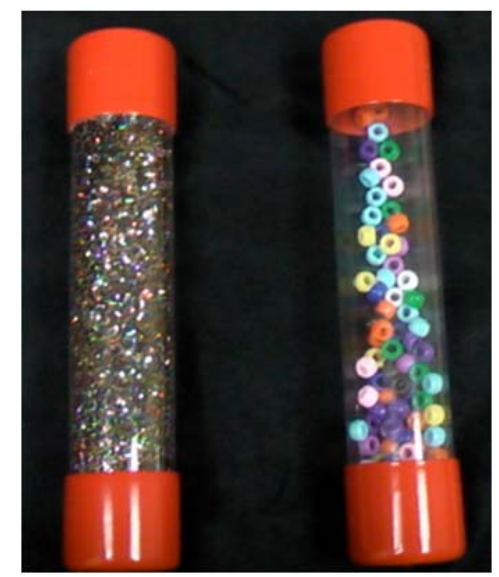

FIGURE 1. Sample of a quiet (glitter-filled) and a loud (bead-filled) objects used as stimuli in the experiment.

Test phase. The experimenter excused herself and left the room. She quickly returned with the doll in its bassinet. Using a hushed tone, the experimenter described the doll as being asleep, “Look, the baby's sleeping.” The experimenter told half of the children (wake group, randomly assigned) that it was time to wake up the doll. The other half of the children (don't wake group) was told not to wake the doll.

In both groups, the experimenter presented objects from the first set and, in a hushed tone, asked the children which one they wanted. After the choice, a 10-s response period was timed starting from the first touch. The experimenter then removed the first set of objects. After another reminder either to wake or don't wake the doll, the experimenter presented the second pair of toys to the children following the same protocol. The adult experimenter adopted an interested, neutral face throughout the choice and the response periods.

To test for any unintended, subtle cuing by the experimenter, we isolated the video segments showing when the experimenter offered the pairs of object in each phase. Research assistants, kept blind to the purpose of the study or group assignment, judged which of the two objects the experimenter might have wanted the child to choose, providing a dichotomous 
forced-choice score. For each trial, the adults' choices were compared to the choice the child made. As expected and in line with the experimental protocol, the experimenter's behavior was not judged to vary: The scorers could not predict the children's choices at greater than chance levels $(M=52 \%$ of trials, $S D=.03), t(5)=1.21, p=.28, d=.48$.

\section{Dependent Measures and Scoring}

Research assistants, blind to experimental group, scored the children's behaviors during the familiarization and the test phases from the videos. There were two dependent measures.

Choice. For each familiarization and test phase, we recorded whether the child chose the loud $(+1)$ or the quiet toy $(-1)$. A choice was defined as the item the child first pointed to or touched. Rarely (2 trials), the child did not make a clear first choice. This response was scored as a 0 . The scores were summed across each child's two trials to form a choice score ranging from 2 to +2 for each child.

Sound intensity. We analyzed the sound intensity from the videos using Praat speech analysis software (Boersma \& Weenink, 2005). The decibel (dB) level of each 10-s response period was measured (Praat software), and the maximum sound intensity produced by the child was recorded. A mean sound intensity score was calculated separately for the familiarization and the test phases. This machine measurement of sound level captured all sounds produced by the child, including shaking either of the objects, banging them on the table, and the loudness of child's own vocalizations. Two children's data were excluded from these analyses because of a problem with the sound on the video record.

Scoring agreement. Scoring agreement was assessed by having an independent coder, also blind to test groups, score a randomly chosen $25 \%$ of children. The interrater agreement for the choice score was $100 \%($ kappa $=1.0)$; the sound-intensity score was machine-measured and thus no scorer agreement was calculated.

\section{Results}

Preliminary checks showed no significant effects of trial $\left(1^{\text {st }}\right.$ or $\left.2^{\text {nd }}\right)$ on the choice or sound intensity score. We collapsed across this factor for subsequent analyses.

The choice score was analyzed with a 2 × 2 x 2 ANOVA, with phase (familiarization or test) as the within-subjects factor and age ( 2 or 3 years) and experimental treatment group (wake or don't wake) as between-subjects factors. There was a significant Group x Phase interaction, $F(1,44)=9.48, p=.004, \eta_{p}{ }^{2}=.18$ (Figure 2A). Follow-up $t$-tests revealed that children in the wake group had significantly higher choice scores (positive scores indicate choosing the loud object) in the test phase than in the familiarization phase, $t(23)=3.32, p=.003, d=.97$. Thus, the children who were tasked with waking the doll shifted to choose the loud object relative to their baseline choice. In the don't wake group, there was no significant change between familiarization and test phases, $t(23)=1.00, p=.33, d=.21$. 


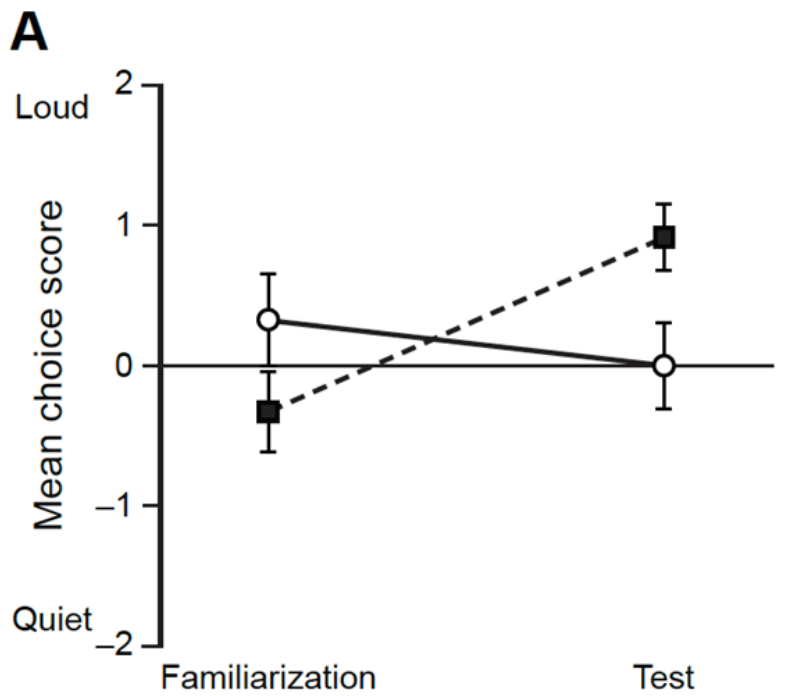

Test phase
B

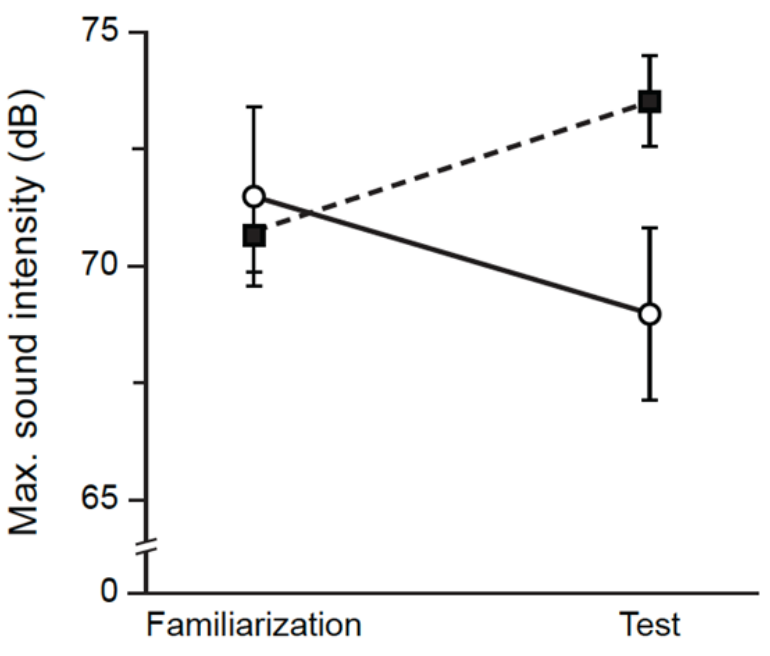

Test phase

- - - Wake group -0 - Don't wake group

FIGURE 2. (A) Mean number of trials (of 2) on which the child chose the loud (positive values) or quiet objects (negative values), and (B) mean maximum sound intensity as a function of test phase and experimental group. Error bars show standard errors.

To examine whether children changed their sound intensity when manipulating the objects, we conducted a 2 (phase) x 2 (age) x 2 (group) ANOVA for maximum sound intensity. This analysis revealed a significant Phase $\mathrm{x}$ Group interaction $F(1,42)=10.72, p=.002, \eta_{p}{ }^{2}$ $=.20$ (Figure $2 \mathrm{~B}$ ). The maximum sound intensity produced by children in the don't wake group was significantly lower in the test phase than in the familiarization phase, $t(21)=2.32, p=.03, d$ $=.29$. The reverse was seen in the wake group; children had higher sound intensity scores in the test than in the familiarization phase, $t(23)=2.43, p=.02, d=.64$. It was possible that children who chose loud toys always made louder sounds than children who chose quiet objects. Note, however, that the sound intensity produced by a child was not limited by their choice. After the child chose an object, the other object was also placed on the table, and thus, all children had the opportunity to produce the same range of sound intensities. Also, children could bang the tube with feathers on the table and it would make a loud sound, or they could shake the tube with beads gently and it would make a soft sound. Indeed the object choice scores (summed across phase and trial) were not significantly correlated with the mean sound intensity scores, $r(46)=$ $.20, p=.19$.

A total of 10 of the 48 children (21\%) made linguistic comments relevant to the task. Six children talked about waking the baby (e.g., "I want to wake up the baby,"); all of these were in the wake group. Four children's comments involved being quiet or letting the baby sleep (e.g., 
“Quiet," “Don’t want to wake baby up.”); all of these were in the don't wake group. These descriptive data support the idea that at least some children were intentionally moderating their own behavior to achieve the wake/don't wake goal.

We categorized children into groups based on whether they were singletons or had at least one sibling, on the grounds that having siblings may provide relevant experience. In the wake group 19 children had a sibling ( $n=10$ two-year-olds, $n=9$ three-year-olds). In the don't wake group 18 had a sibling ( $n=9$ two-year-olds and $n=9$ three-year-olds). There were no significant effects for the choice score, however, there were significant effects in the predicted direction for the sound-intensity measure (a significant Phase x Group x Sibling interaction), $F(1,43)=5.21, p=.03, \eta_{p}{ }^{2}=.17$. Children who had a sibling showed the expected pattern, with significant increases in sound intensities from the familiarization to test phase in the wake group $\left(n=19, M_{\text {Fam }}=70.95 \mathrm{~dB}, S D=3.51 ; M_{\text {Test }}=74.56 \mathrm{~dB}, S D=4.43\right), t(18)=3.21, p=.002, d=$ .90 , and significant decreases in the don't wake group $\left(n=14, M_{\text {Fam }}=73.36 \mathrm{~dB}, S D=4.83 ; M_{\text {Test }}\right.$ $=69.94 \mathrm{~dB}, S D=4.08), t(13)=2.36, p=.04, d=.76$. In contrast, singletons showed no significant change in sound intensity between the familiarization and the test phases: for the wake group, $t(4)=.73, p=.50, d=.46\left(n=5, M_{\text {Fam }}=71.74 \mathrm{~dB}, S D=3.99 ; M_{\text {Test }}=70.30 \mathrm{~dB}, S D\right.$ $=1.83)$; for the don't wake group, $t(7)=.50, p=.63, d=.03 .\left(n=8, M_{\text {Fam }}=69.28 \mathrm{~dB}, S D=\right.$ $\left.11.89 ; M_{\text {Test }}=68.90 \mathrm{~dB}, S D=12.27\right)$.

\section{Discussion}

Compared to the rich body of research about young children's understanding of other people’s visual perception, comparatively little is known about toddlers’ grasp of others' auditory perception. The current results suggest that 2- to 3-year-old children, particularly those with siblings, have an understanding of the behavioral or psychological effects of different types of sound. The children who were told that the goal was to wake the doll produced higher intensity sounds, whereas the children who were told not to wake the doll produced less intense sounds. Additionally, children who were told to wake the doll significantly more often choose the loud object.

What explains the children's behavior? One possibility is that children use the purely script-based knowledge of "being quiet when a baby is sleeping" when confronting this task. However, we do not think this is sufficient to explain the findings. The adult avoided giving direct instructions on how to behave; children were never told to be quiet or to make noise. Children had no prior experience with these particular objects, because the novel stimuli were created for this study. All children saw the same doll and were told that it was sleeping. If children's behavior was triggered solely by having their attention brought to a sleeping doll stimulus, they should have played quietly in both conditions. Instead, children systematically changed the intensity of their sound production based on the experimental condition. 
We favor the idea that children have a rudimentary understanding of the consequences of sounds on others' perception and behavior. There are at least four developmental mechanisms that could underlie for the obtained pattern of results. The two we will discuss first capitalize on the bidirectional "Like-Me" mechanism for social-cognitive development (Meltzoff, 2007, 2013). First it is possible that children draw on their own self-experience with sounds to make sense of the scenario. Loud noises disturb children's own sleep, providing opportunities to learn the sound-psychology covariation — when the children awake in a startle, the loud sound is often still present. A child may use this self-experience as a basis for inferring that because loud /soft sound affect me in particular ways, the sounds affect others in similar ways. Noisy siblings may provide more self-experience along these lines. Second, children may also learn about audition by observing the statistical regularities in other people's responses to noise. Children with siblings have increased opportunities to observe the effect of noise on sleepers. Just as observing the structured behavior patterns of others influences children's imitation and understanding of visual perception (Meltzoff, 2013; Williamson \& Meltzoff, 2011), it may also play a role in children's understanding of auditory perception.

Third, children may learn about others' auditory perception from parental linguistic explanations about the interplay of sound, sleeping, and waking. Children with siblings have more occasions to hear such linguistic explanations, which could accelerate their grasp of the idea that the loudness of sounds affects mental states (Dunn, Bretherton, \& Munn, 1987; Jenkins, Turrell, Kogushi, Lollis, \& Ross, 2003). Fourth, children with siblings may be better at engaging in the pretend scenario of acting "as if" the doll is asleep or awake, and thus better at showing their understanding in the current task. These various possibilities are not mutually exclusive and are in line with previously reported benefits of siblings on children's developing mental state understanding (for review, see Astington \& Hughes, 2013).

The literature on visual perception makes a distinction between Level-1 versus Level-2 perspective-taking (Flavell, 1992, 1999; Flavell, Everett, Croft, \& Flavell, 1981). It might be argued that the current results manifest a Level-1 of understanding of auditory perception: The children had to recognize that a loud sound would serve as a wake-up call. However, the current results arguably exceed a classical Level-1 task, because both objects made some sound. The child was not choosing between a sound-making object versus a silent one, which presumably would be an easier task. The child's crucial decision was the type (loud/soft) of sound to produce. One could argue that the current study is more analogous to a vivid/faint visual impression (Flavell, Flavell, Green, \& Wilcox, 1980), which exceeds the access/no access limit of classical Level-1 perspective-taking. These findings feed into a growing interest in reconceptualizing the Level-1 to Level-2 distinction in children's perspective taking (Flavell, 2004; Moll \& Meltzoff, 2011; Moll et al., 2013). 
An interesting and largely unexplored consideration is children's understanding of the properties of different sensory organs. Ears are less salient than are eyes on the face: Eyes are frontal, and ears are lateral and often obscured (e.g., by hair or hats). The morphology of the human eye has evolved to attract attention. Human eyes have a white sclera surrounding a darker iris and pupil (Kobayashi \& Kohshima, 2001), but ear morphology does not have such an attention-getting design. It is possible that young children have difficulty identifying the psychological function of ears, their role in ambient information pickup, and how different barriers affect different modalities (earphones block external audition but not vision). These specific factors were not manipulated in the current experiment, and an interesting follow-up would be to explore them systematically, with the goal of testing the scope of children's grasp of auditory perception and whether it lags behind their understanding of visual perception.

In summary, toddlers not only know about other people's visual contact with distal objects, they also have at least a nascent understanding of auditory contact. Children as young as two years old are registering that louder versus softer sounds engender different behavioral and psychological consequences in others; and children with siblings — who presumably have more experience with the effects of sounds on self and others-perform better on this task, suggesting a role for social learning. Crucial for developing a mature social cognition is the understanding that others' auditory experience of the same event may differ from their own: What I hear is different from what you hear. This grasp of audition probably exceeds the mind of the 2-yearold, but builds on the earlier understanding reported here.

\section{References}

Astington, J. W. \& Hughes, C. (2013). Theory of mind: Self-reflection and social understanding. In P. D. Zelazo (Ed.), The Oxford handbook of developmental psychology (pp. 398-424). New York, NY: Oxford University Press. Baldwin, D. A., \& Markman, E. M. (1989). Establishing word-object relations: A first step. Child Development, 60, 381-398.

Bangerter, A. (2004). Using pointing and describing to achieve joint focus of attention in dialogue. Psychological Science, 15, 415-419.

Boersma, P., \& Weenink, D. (2005). Praat: Doing phonetics by computer (Version 4.3.01) [Computer program]. Retrieved from http://www.praat.org/

Brooks, R., \& Meltzoff, A. N. (2002). The importance of eyes: How infants interpret adult looking behavior. Developmental Psychology, 38, 958-966.

Dunn, J., Bretherton, I., \& Munn, P. (1987). Conversations about feeling states between mothers and their young children. Developmental Psychology, 23, 132-139.

Flavell, J. H. (1992). Perspectives on perspective taking. In H. Beilin \& P. B. Pufall (Eds.), Piaget's theory: Prospects and possibilities (pp. 107-139). Hillsdale, NJ: Erlbaum.

Flavell, J. H. (1999). Cognitive development: Children's knowledge about the mind. Annual Review of Psychology, 50, 21-45.

Flavell, J. H. (2004). Theory-of-mind development: Retrospect and prospect. Merrill-Palmer Quarterly, 50, $274-290$. Flavell, J. H., Everett, B. A., Croft, K., \& Flavell, E. R. (1981). Young children’s knowledge about visual perception: Further evidence for the Level 1-Level 2 distinction. Developmental Psychology, 17, 99-103. 
Flavell, J. H., Flavell, E. R., Green, F. L., \& Wilcox, S. A. (1980). Young children’s knowledge about visual perception: Effect of observer's distance from target on perceptual clarity of target. Developmental Psychology, 16, 10-12.

Flom, R., Lee, K., \& Muir, D. (2007). Gaze-following: Its development and significance. Mahwah, NJ: Erlbaum.

Jenkins, J. M., Turrell, S. L., Kogushi, Y., Lollis, S., \& Ross, H. S. (2003). A longitudinal investigation of the dynamics of mental state talk in families. Child Development, 74, 905-920.

Johnson, S. C., Ok, S.-J., \& Luo, Y. (2007). The attribution of attention: 9-month-olds' interpretation of gaze as goaldirected action. Developmental Science, 10, 530-537.

Kobayashi, H., \& Kohshima, S. (2001). Unique morphology of the human eye and its adaptive meaning: Comparative studies on external morphology of the primate eye. Journal of Human Evolution, 40, 419-435.

Lee, K., Eskritt, M., Symons, L. A., \& Muir, D. (1998). Children’s use of triadic eye gaze information for “mind reading.” Developmental Psychology, 34, 525-539.

McGuigan, N. (2007). Can 2- and 3-year-old children be trained to perform visual perception tasks? British Journal of Developmental Psychology, 25, 327-334.

Melis, A. P., Call, J., \& Tomasello, M. (2010). 36-month-olds conceal visual and auditory information from others. Developmental Science, 13, 479-489.

Meltzoff, A. N. (2007). 'Like me’: a foundation for social cognition. Developmental Science, 10, 126-134.

Meltzoff, A.N. (2013). Origins of social cognition: Bidirectional self-other mapping and the "Like-Me" hypothesis. In M. Banaji \& S. Gelman (Eds.), Navigating the social world: What infants, children, and other species can teach us (pp. 139-144). New York: Oxford University Press.

Moll, H., Carpenter, M., \& Tomasello, M. (in press). Two- and three-year-olds know what others have and have not heard. Journal of Cognition and Development. doi:10.1080/15248372.2012.710865

Moll, H., \& Meltzoff, A. N. (2011). How does it look? Level 2 perspective-taking at 36 months of age. Child Development, 82, 661-673.

Moll, H., Meltzoff, A. N., Merzsch, K., \& Tomasello, M. (2013). Taking versus confronting visual perspectives in preschool children. Developmental Psychology, 49, 646-654.

Moll, H., \& Tomasello, M. (2006). Level 1 perspective-taking at 24 months of age. British Journal of Developmental Psychology, 24, 603-613.

Moses, L. J., Baldwin, D. A., Rosicky, J. G., \& Tidball, G. (2001). Evidence for referential understanding in the emotions domain at twelve and eighteen months. Child Development, 72, 718-735.

Phillips, A. T., Wellman, H. M., \& Spelke, E. S. (2002). Infants' ability to connect gaze and emotional expression to intentional action. Cognition, 85, 53-78.

Repacholi, B. M. (1998). Infants' use of attentional cues to identify the referent of another person's emotional expression. Developmental Psychology, 34, 1017-1025.

Repacholi, B. M., \& Meltzoff, A. N. (2007). Emotional eavesdropping: Infants selectively respond to indirect emotional signals. Child Development, 78, 503-521.

Repacholi, B. M., Meltzoff, A. N., \& Olsen, B. (2008). Infants' understanding of the link between visual perception and emotion: "If she can't see me doing it, she won’t get angry." Developmental Psychology, 44, 561-574.

Williamson, R.A., \& Meltzoff, A.N. (2011). Own and others' prior experiences influence children's imitation of causal acts. Cognitive Development, 26, 260-268.

Woodward, A. L. (2003). Infants' developing understanding of the link between looker and object. Developmental Science, 6, 297-311.

Yaniv, I., \& Shatz, M. (1988). Children's understanding of perceptibility. In J. W. Astington, P. L. Harris, D. R. Olson (Eds.), Developing theories of mind (pp. 93-108). New York, NY: Cambridge University Press. 